DOI: $10.1515 /$ ausfm-2018-0003

\title{
“Let Man Remain Dead:” The Posthuman Ecology of Tale of Tales
}

\author{
Francesco Sticchi \\ Oxford Brookes University (United Kingdom) \\ E-mail: francescosticchi@gmail.com
}

\begin{abstract}
In this essay I analyse Matteo Garrone's Tale of Tales (2015) within the perspective of embodied cognition. I consider film experience as an affective-conceptual phenomenon based on the viewer's embodiment of the visual structures. Baruch Spinoza stands at the foundation of my analytical approach since his thought was based on the absolute parallelism between the body and the mind. This paradigm redefines anthropocentrism and rejects dualism; however, the criticism of the rationalist ideal is also one of the main characteristics of the film Tale of Tales: by staging baroque and excessive characters, it allows the viewer to embody a notion of subjectivity that is performative and relational. Therefore, by combining the cognitive analysis of the film with my theoretical framework I will present a radical criticism of abstract rationality and present an ecological idea of the human.
\end{abstract}

Keywords: embodied cognition and cinema, sad passions, becoming-animal, posthuman, Spinoza.

Tale of Tales (2015) is a fantasy film based on the $17^{\text {th }}$-century collection of fairytales Lu cunto de li cunti by the Neapolitan poet Giambattista Basile. More precisely, it readapts three tales: La Cerva Fatata (The Enchanted Doe), La Vecchia Scorticata (The Two Old Women), La Pulce (The Flea). The first tale describes the obsessive and destructive maternal love of the queen of Longtrellis (Salma Hayek) for her son Elias. The second deals with two old sisters, Dora (Hayley Carmichael) and Imma (Shirley Anderson), who try to seduce the king of Strongcliff (Vincent Cassel), and crave for youth and wealth. Finally, the third tale portrays the morbid passion of the king of Highhills (Toby Jones) for a flea, which makes him lose his throne and his daughter Violet.

As it happens in many forms of popular narrative, these tales are intended to express a moral message and an existential admonishment. At the end of these fables in the original text, for instance, there is a small sentence that highlights the 
teachings communicated by a particular story, which are concepts and notions that reflect the moral values of the baroque age. What is common in the three tales also portrayed in the film, is a sense of existential limitation, which in the end punishes arrogance and envy, and which reminds the readers of their precarious conditions in life (cf. Basile 1995, 52, 87, 98). Furthermore, these admonishments work also as a kind of memento mori (remember that you have to die). As a consequence of this conceptual dimension, the characters of the fables are humans driven by passions, illusion and desires. They do not behave as rational and controlled individuals and, during the events of the different stories, they experiment, at their own expense, the vacuity and foolishness of their choices. Nonetheless, it should be noticed that the moral teachings of the text are also intended to encourage the readers or listeners of the time to accept their own social role and position.

In my opinion, the film works in a similar way by establishing visual concepts and an interactive dimension that stresses the role of passions (particularly sad passions) in defining the behaviour of the characters, even though it does not convey exactly the same moral values. From a thematic point of view we can say that the three tales all deal with obsessions and, in order to stress this conceptual affinity, they are intersected in the narration. At the same time, the film develops a peculiar affective-conceptual dimension, which allows us to critically examine the principles of modern humanism.

\section{Theoretical Framework and General Coordinates of the Experience}

My analytical account falls within the framework of cognitive film theory (CFT), and focuses on the capacity of film viewers to associate every affective element they experience with concepts and ideas, thus identifying film experience as an embodied phenomenon that integrates sensation and intellection. As Adriano D'Aloia and Ruggero Eugeni affirmed, we should talk of viewers as organisms, as bodies and minds that participate in the experience in their entirety (D'Aloia and Eugeni 2015, 20). I also combine these notions with the neurocognitive studies of Vittorio Gallese and Michele Guerra, who outlined an innovative description of embodied simulation, namely the affective-cognitive process, enacted by mirror neurons and empathic operations, which indicates a resonance and contiguity between the screen and the viewer (Gallese and Guerra 2015, 53-55). Therefore, in film experience we are able to embody the on-screen actions, to empathize with the emotional states of the characters and to interact with the aesthetic 
features of the product (camerawork, colours, sound effects, cutting rate, scenic design). We also have to notice the centrality of image schemas and kinaesthetic expressions in cinema, audiovisual spatial metaphors that synthesize complex intellectual models, through which we access to characters' subjectivities and to contextual concepts such as ideas of time, of memory and even general moral notions (cf. Coëgnarts and Kravanja 2015, 274; Fahlenbrach 2007, 107). Indeed, we can generate conceptual models that are useful to empathize with characters or that provide us with a general sense of the experience (cf. Smith 1995, 21; Plantinga 2014, 143). Furthermore, I integrate cognitive film theory with philosophical analyses to highlight the "ecological" and relational nature of the medium, and our capacity to "physically" interact with concepts and complex subjectivities through the embodiment of blocs of sensations. In general, my approach rejects every dualistic distinction between emotion and reason, and identifies film viewers as relational agents who participate in the experience with all the potentialities of their embodied minds. Therefore, I would argue that film experience should be analysed as an interactive phenomenon, which audiovisualizes body states and relational systems and whose characteristics emerge as performative and dialogical events.

Going back to the film, as the director himself declared in an interview, Tale of Tales was meant to have a strong visual impact intended to create a general sense of marvel (Garrone 2015). We can notice the prominent role that many lowlevel features have in this particular experience to establish specific interactive coordinates. For instance, the frequent use of saturated colour tones enhances particular (negative) sensations and narrative situations, and contributes in giving a "dark" and grotesque atmosphere to the experience. We can observe the constant presence of gloomy tints and, at the same time, of bright colours to highlight the luxury of clothes, jewels and of the furniture. Moreover, the recurrent presence of fog and mist strengthens the fairytale and mysterious environment. In this sense, the employment of magnificent baroque and medieval architecture (such as Castel del Monte, and the Castle of Donnafugata), of very peculiar landscapes and sumptuous internal locations is helpful in generating a whole sense of fabulous excess. By following the studies of Kathrin Fahlenbrach and Codruța-Elena Morari, we could affirm that architectural and spatial metaphors have an important role in influencing emotional and intellectual operations in the viewer (Fahlenbrach 2007, 113). In the case of this film then, we can notice a typical conceptual association that connects baroque architecture and a sense of excess and incapacity to control perception (Morari 2007, 94-95). Even the costumes and makeup (which should 
reproduce the $17^{\text {th }}$-century style) are characterized by this very luxurious tone. In particular the clothes of the queen of Longtrellis, who usually wears very long and elaborate dresses of powerful colours (mainly black and dark red), effectively convey the emotional intensity and the morbid desires of the figure. According to Carl Plantinga, these and other aesthetic elements, such as the cutting rate, or the use of the soundtrack, are cognitively combined by viewers to generate the mood of a particular experience, the film's overall affective-intellectual charge (Plantinga 2014, 145). This cognitive and emotional dimension pervades the film in its entirety and frames the viewer's interaction, thus influencing the meaning and significance of particular actions and elements (148-149). Furthermore, Plantinga maintains that these affective elements help us in recognizing the filmic genre that we are perceiving, or the scenario, an expression that identifies the type of interaction we participate in and the actions to be performed within this experiential context. However, although mood and scenario are synthetic and unifying conceptual models, they must not necessarily be coherent and fixed. In this film, indeed, we can notice the presence of different experiential dimensions which are connected with heterogeneous tones and atmospheres.

As the aesthetic elements discussed before already demonstrate, viewers are immersed in fairytale and mysterious mood, but, at the same time, they are also pervaded by excessive and gory elements (which are frequent in all the three stories), which in turn are accompanied by an ironic and grotesque style. The combination of these different features generates a filmic world dominated by a sense of excess and morbidity, an experiential dynamics that the characters inhabit and the viewers participate in. These general cognitive elements help viewers to frame the destructive and passionate behaviour of the characters and motivate their actions by creating a sense of existential instability, which combines affections of marvel and horror.

\section{Engaging Sad Passions and the Connections with Spinoza's Philosophy}

The baroque and fantastic tone of the film permeates the conceptualization of both the environment and the characters. I would argue that this effect is reached also through the description of fictional figures that seem lacking of a psychological depth or of a structured inner being. Viewers have the sensation that all their emotional states and reactions are externalized and they never appear in a contemplative or reflective position. Similarly, in the original 
text of the fairytales, the names of kings and queens are not known, they can be recognized only through their titles - a stylistic choice that reiterates their fantastic nature, but one that also frames them as prototypical figures more than coherent psychological subjects. Furthermore, this expressive element is strengthened by the fact that very little dialogue is present during the narration. The sequences depicting verbal confrontations are characterized by slow cutting rate and by the use of minimal camera movements, which reduce the emotional and conceptual centrality of the dialogues, particularly for the purpose of engaging the psychology of the characters. Because of their frequent lack of climactic tension, these exchanges tend to have an evocative and poetic tone that enhances the sense of irrationality surrounding the protagonists of the tales.

The initial sequence of the film expresses this aesthetic and conceptual choice more emblematically by completely abolishing dialogue. This scene presents the main characters of the tale The Queen; it lasts around three minutes and fifteen seconds, and shows the arrival and the exhibition of a company of jesters at Longtrellis castle, which is interrupted by the queen's nervous reaction to the discovery of the pregnancy of an actress. No word is uttered for the whole duration of this scene; viewers receive diegetic sound effects, the soundtrack is characterized by a placid and dreamlike motif for strings and xylophone, and expressions of surprise, joy and laughs can be heard in reaction to the show. The centrality of these nonverbal expressions in this prologue and the general lack of importance of dialogues have the function of cognitively influencing the viewer by establishing some essential interactive and conceptual coordinates of the experience. In particular, these elements give viewers the opportunity to directly embody emotional states (surprise, marvel, anger) and to understand their importance in the dynamics of the film against a more clear and linear development of the story and of the psychology of the characters. Thus, by abolishing dialogue, the film facilitates our understanding of the characters as pure blocs of sensations and passions, as intensive figures pervaded by desires and affections. The short sequence that depicts the queen of Longtrellis eating the heart of the aquatic dragon (it lasts about thirty seconds and consists of a slow forward tracking shot that ends in a close up) effectively synthesizes this stylistic choice and makes viewers sense the "irrational" dimension of the film. The queen is positioned at the centre of the image, wearing a long black dress and eating with voracity this enormous organ, while her face is getting covered with blood [Fig. 1]. In contrast, the entire surroundings (the wall in the background and the table where she is eating) are completely white, thus emphasizing the gruesome and monstrous aspect of the 
sequence. Not incidentally, the image of the queen devouring the dragon's heart was chosen as one of the film's posters since it conveys the excessive and baroque nature of the movie. The animalistic obsession of the queen for her motherhood, which will lead her to self-destruction, is conceptualized in the sequence of the king's funeral. The general atmosphere is lugubrious in accordance with the type of ceremony and because of the nocturnal setting. At a certain point, after having shown the participants to the funeral, the camera moves upon the king's corpse, which is carried on a stretcher. In the foreground, we perceive the close up of the body, whereas in the background the queen appears in a palanquin, completely absorbed by her son, who she carries and caresses while remaining completely indifferent to the death of her husband. After the description of this contrast, the camera moves to a close up of the queen, which shows her indifference for the king's departure and her devotion for the newborn son even clearer. Thus, viewers can perceive and participate in the queen's intense love for Elias through the contrast generated by the relation between the background and the foreground. Moreover, in accordance with Murray Smith's studies on emotional participation (1995, 102), this affective conceptualization allows us to align with the character and to understand the meaning of her future actions. Smith affirms that psychological mechanisms of emotional involvement allow viewers to empathize with a negative character (like the queen) and to understand the sensations and ideas that affect her $(1999,220)$. However, these aspects of her behaviour do not prevent us from experiencing actions and moments of absolute tenderness produced by her genuine motherly love, or from appreciating her affective and conceptual complexity. It is also interesting to notice how, apparently, this emotional force that dominates the queen prevents her from understanding the admonishments of the necromancer (Franco Pistoni), who repeatedly alerts her about the risks of her own choices. We can infer that in these moments she only listens to what satisfies her wishes or feeds her passion. In the end, when she turns into a flying monster, it will be exactly her absolute love that will block her from attacking Elias (who rushed to help Jonah, his twin born from a maiden servant), and that will lead her to be definitively separated from her son.

Similar emotional developments can be perceived in the case of other characters as well. The two sisters, Dora and Imma, for instance, are possessed by a destructive desire for youth and richness, which, as it is easy to observe, is also motivated by their miserable condition. Dora is moved by the foolish desire to become the king's lover and is ready to hurt herself and to risk her life for this purpose. Furthermore, although she becomes a beautiful woman, 
the epilogue shows that her body is aging fast and then she flees from the final ceremony. Viewers, thus, can perceive the futility and precariousness of her illusions, which rapidly dissolve and bring her back to her previous state. Imma, on the other hand, follows a different emotional path. She is not attracted to the king and tries to stop her sister from completing her absurd plan. However, her emotional world changes when she participates in Dora's wedding feast. The visual conceptualization of the sequence helps the viewers in embodying and simulating Imma's affective dimension and in perceiving her complete emotional transformation. The camerawork is essentially based on following with a steadicam her immersion into the aristocratic environment. Most of the time, she remains in the centre of the image (in a medium close up perspective) and her reactions of marvel and admiration can be clearly observed, thus viewers can empathize with these affective states (Smith 1995, 98-99) [Fig. 2]. Furthermore, by analysing this sequence with the instruments elaborated by Maarten Coëgnarts and Peter Kravanja $(2015,286)$ we can clearly associate Imma's act of looking (association between eyes and understanding) with her growing sense of marvel, which is in turn connected with the atmosphere surrounding her. Furthermore, the continuous focus on her face and expressions makes the viewers embody a sense of complete engagement in the events, which, in turn, manifests the emerging desire of the character. Indeed, the splendour of the ceremony and her sister's beautiful appearance make Imma crave to remain at the palace in order to come out of her previous economic and existential condition [Fig. 3]. When the feast ends, she does not want to leave and instantaneously reveals to everyone that she is the queen's sister (against what Dora recommended because nobody would have believed her) and that, therefore, she needs to remain at the castle. Imma is also shown observing her sister making love with the king with a morbid curiosity (she even gets close to the bed) and we can infer that it is in accordance with these excessive and pervasive desires that, later, she flays herself with the purpose of becoming young again. The final images of the tale depict her, covered with injuries, moving towards the castle. In this small sequence the steadicam follows her and initially remains on her back, while viewers can easily notice the terrified reactions of the people observing her. The fairytale soundtrack (a serene motif for xylophone) is in conflict with the dreadful elements of the sequence, thus producing a disturbing contrast that is enhanced when Imma is shown from a frontal point of view and she appears as a moving corpse. Thus, we directly perceive the tragic end of her foolish desires with a traumatic image that conceptually connects with the limitations of human existence. 
Similarly, an ironic attitude can be detected in the description of the king of Strongcliff, who should represent an insatiable libertine and seductive man, but who often acts in a grotesque and comic fashion. Just like the queen with her maternity, and the two old sisters with their craving for youth, the king of Highhills is possessed by a destructive obsession as well. He has a maniacal interest in, and love for a flea, which makes him, at first, overlook his office duties, then lose her daughter through an act of absolute arrogance. However, the passion that affects this character will be analysed later since it directly involves the relation between the human and the animal.

In general, it can be affirmed that the film presents individuals who are passive agents of desires, which leads them to self-destruction. This description of the passions and the focus on the desiring nature of humankind connect the film with the philosophy of Baruch Spinoza, whose work I combine with my embodied cognitive account. As Heidi Morrison Ravven affirmed, Spinoza was a forerunner of theories of embodied cognition and rejected every dualistic distinction, such as the Cartesian body-mind division and the Nature-Culture split, and integrated affection and conceptualization (Ravven 2003). For this reason, he thought that we exist as relational and ecological beings always involved in an emotional and desiring tension towards the world, which is mainly intended to preserve and increase our state (conatus). Therefore, according to Spinoza, wise and free individuals are those who are able to connect and compose themselves with the environment and other beings in the most productive, creative and, therefore, ethical way (Spinoza 2011, 1579). However, because of their limited nature, humans are not directly able to control their behaviour and, therefore, they are mostly passive agents with an inadequate understanding of the world. Furthermore, because of the affective and embodied nature of thought, human intellection is always linked with sensations, which are sad passions in the case of an inadequate knowledge, and joyful emotions when new connections and a productive understanding of things are created. Sad passions are often connected with resentment, envy, fetishism and narcissism, which reflect a destructive tension and the incapacity to change. This theoretical framework involves the rejection of higher abstract rationality or of transcendent systems of judgment, and that every action or intellectual model should be evaluated in reason of its connective or destructive power. For this reason, Spinoza maintained that the mad and the wise share the same natural right to exist (Spinoza 2011, 1437, 1487). Probably the most challenging aspect of Spinozian philosophy is that it clashes with the tradition of enlightenment and rationalist thought. Indeed, 
Spinoza denies the abstract nature of reason and decentralizes the mind, which is relational and in a continuous state of combination with the world. Moreover, his thought refutes the description of individuals as coherent and fixed beings. In a Spinozian perspective, humans are not closed subjects with a structured inner emotional world, but blocs of sensations, transformations and becoming. In this sense it can be stated that the humanist ideal of a controlled and serene rationality, the moral values that fulfil this ideal together with the positivist model of progress they entail are false to the extent they all deny the desires and the relations that produced these same intellectual models (cf. Braidotti 2013, 31-32; Spinoza 2011, 1437). These philosophical notions allow us to affirm that Tale of Tales displays a Spinozian reflection on human condition by presenting different subjects who are victims of sad passions and fetishistic desires. In this sense, the baroque setting of the film assumes strong conceptual valence since it, by stressing the role of emotions in life, defines an ontology based on the immanence of thought and a vision of the human as affective and relational. However, it would be possible to argue that, as in the tradition of fairytales, the film provides the viewer with morals about desires and their dangerous nature. Nonetheless, what is really Spinozian in the film is the attention upon affectivity, the description of characters who are pervaded by emotional states and whose actions are determined by these affective forces. We have seen that, for instance, the lack of dialogues, where the characters could more clearly reveal personal reflections or explain their behaviour, is functional to increase the sensations that pervade the experience. Furthermore, it can be noticed that the desires depicted in the film are not simple affections but entire cognitive states. For instance, the absolute love of the queen for Elias is not a simple obsession, but a general intellectual dimension that prevents her from understanding the admonishments of the necromancer or from accepting the friendship of her son with Jonah. Similarly, it has been discussed above how Imma's desire to remain in the pleasurable state experienced during the wedding feast and the envy for her sister's beauty push her to accept her destruction as if it was her realization (to paraphrase a famous Spinozian question; cf. Spinoza $2011,1063)$. It can be noticed that the characters of the film generate a conceptual world around emotional coordinates that viewers can embody and simulate, thus understanding the meaning of their actions and empathizing with their choices.

However, this embodied simulation should not be considered as a passive activity based on the reproduction of affective states; on the contrary, it is a dialogical exchange between the embodied mind of the viewer and the affective and intellectual world expressed on the cinematic screen. Indeed, this point 
connects us also with Spinoza's notion of empathy, which, in his views starts from a state of emotional contagion or affective resonance between bodies and allows the simulation of the actions of other individuals. This process, which Spinoza defines as the imitation of affects (2011, 1353-1365), is not one's simple projection into someone else's state, but a continuous negotiation between individuals. In this intersubjective space we do not simply imitate the others' actions, we also assign a meaning and a value to those actions by 'reading the mind' of the others and by trying to understand their subjective-experiential worlds. For this reason, the empathic process is not neutral and mechanistic; it requires an active participation of the viewer and, therefore, its effects are impossible to predict and can lead to the creation of new relational forms of life, but also to mutual destruction and mortification. Spinoza's model of intersubjectivity is compatible with Vittorio Gallese's shared manifold hypothesis, which describes human activity as a continuous mutual enactment between individuals based on the construction of a "we-centric blended space:" a common dynamic ecological dimension (Gallese 2003; Ravven 2003). By applying these theoretical instruments, one can observe how viewers are able to share the world of the characters, even though they express values and desires that they do not agree with (cf. Smith 1999, 221) by negotiating and interacting with them on a cognitive and affective level. At the same time, it can be seen how the characters in the film, because of their being possessed by emotional forces, lack the ability to readapt themselves to the world, to understand the needs of other beings, or more simply to follow the advice that they receive during the narration. Therefore, they remain trapped in a condition without escapes, expressing the reactive power of sad passions. The three young characters of the film: Violet, Elias and Jonah, are, on the contrary, forced to clash with these forces and, exactly because of their being the victims of the desires of others, they are able to accomplish a path of maturation, facing parents who express obsessive love or treat their children as mere properties. These young characters are placed in a position that requires more awareness and wisdom from them, which generates an affirmative and positive resistance against the power of sad passions. However, I would argue that their conquest of independence, which couples their entrance into adulthood, is characterized by the discovery of an "emotional intelligence" (which the other characters are lacking of), but this does not constitute a negation of the centrality of affectivity in life. On the contrary, they demonstrate an ability of extending their emotive capacities beyond the narcissistic limits of their ego and, for this reason, they are capable of transforming and of becoming new individuals. 


\section{The Posthuman and the Becoming-Animal}

Our considerations on affectivity, on the ecological dimension of the human, and on the precarious value of abstract rationality make possible a combination of what has been discussed in the previous sections with Rosi Braidotti's (Spinozian) work on the posthuman. Braidotti elaborated this term as a tool to investigate the limits and fallacies of the humanist tradition of Enlightenment and transcendent rationalism. These monumental epistemological frameworks constitute the legacy and the backbone of modernity by determining the structure of our scientific or political thought together with the codification of modern states as rational institutions. Moreover, the humanist tradition involves a standardization of gender and ethnic roles by using white masculinity as its reference point (Braidotti 2013, 24). Indeed, the image that summarizes this ideal is Leonardo da Vinci's Vitruvian Man (1490). However, the issues of contemporary world, such as new discoveries in biogenetics, the schizophrenic nature of late capitalism, new forms of globalized war and ecological catastrophes, ask for a new embodied thought able to challenge these problems and to draw experiential cartographies of our new existential dimension (Braidotti 2013, 4). Nonetheless, this criticism should never be confused with a banal nihilistic and misanthropic condemnation of humanism. The search for new navigation tools is necessary because the impasses we are facing nowadays took shape in the context of modernity and cannot be addressed with the same account that produced them. Not incidentally, today we are experiencing reactive and nostalgic reuses and recodings of humanism that justify war, imperialism and "clashes of civilizations" (Braidotti 2013, 5, 36). Then, Braidotti combines new scientific discoveries with critical thought in a way that overcomes the nature-culture split and the dualistic codifications of thought.

Therefore, a contiguity between the film and this critical approach can be established, since they both deconstruct the humanist ideal by showing our relational constitution, and reveal the affective and physical ground of rationality by externalizing the mind. Braidotti also reflects on the importance of empathy in demonstrating that we do not exist as atomic subjects, but that we generate our identities on an interactive dimension (Braidotti 2013, 78). Hence, she affirms that in the analysis of emotions and affectivity resides the key to consciousness and that, as Spinoza, we need to build a critical materialism able to highlight the intensities and potentialities of thought.

It has already been examined how Tale of Tales depicts of characters driven by desires and sad passions; now I will introduce and analyse, in light of Braidotti's 
notion of posthuman, another fundamental characteristic of the film: the relation and contiguity between the human and the beastly and the metamorphic nature of individuals. Many figures during the narration undergo processes of transformation or show a disturbing contiguity with animals (becoming-animal). Dora changes her look with the spell of a witch, while the queen becomes a monster because of the jealousy for Elias. At the same time, Imma transforms into a living corpse. What is interesting to notice is that the "animalization of the human" in the film is not linked to anthropomorphic descriptions of animals or to moralistic admonishments that condemn the beastly behaviour of humans who act dominated by irrationality. It is a description of an existential common plane where these categories continuously negotiate and transform reflecting the ecological relations in which the human, as cultural and cognitive category, is involved. I would argue that these elements emerge more clearly through the analysis of the passion of the king of Highhills for a flea. Because of the interest in this little creature the king starts neglecting his duties, and then his daughter, whom he eventually sacrifices exactly because of his attraction for the flea. At the beginning of the tale, we see the king completely absorbed in the admiration of the animal and ignoring Violet, who is playing a song for him. Later, in his studio he stings his finger in order to attract the animal with his blood. Here a very interesting detail is shown of the king's finger and of the flea sucking the blood from the injury. Through this image an extreme physical contiguity can be perceived between them, which conceptualizes a sense of interchangeability of the human and the animal. Indeed, after that, we see the king manufacturing little carousels for the flea, and, in general, showing a concrete attachment, which becomes glaring in the sequence that depicts the death of the animal (the flea dies after having become enormous because of excessive nourishment). The emotional bond of the king for the animal is then depicted through a medium shot that shows him sadly lying on its corpse (the action lasts twenty seconds with no words pronounced). [Fig. 4.] Even though the king's behaviour can be judged as morbid and absurd, one can affectively and intellectually align with him (cf. Gallese and Guerra 2015, 108; Smith 1995, 189) and experience an emotional link that shatters the limits of the species and rejects anthropocentrism by placing every being on the same existential level. The king shares an experiential territory with the flea and, therefore, gets involved in a relational continuum that reshapes his nature and that, as Braidotti would say, undermines human supremacy over the species (Braidotti 2013, 80-82). However, although he opens to a direct connection with the animal, the king shows a major contradiction 
in his behaviour. He builds an affective link with the flea but, at the same time, his morbid curiosity for the animal makes him crave for possession and control. Indeed, this negative affective dimension is exemplified by the king trapping the flea into a little box and intensely admiring it through a hand lens or by the fact that he uses the animal's skin as attraction and challenge for his guests. Therefore, this tale (and the others to a minor extent) describes a humanity that transforms and mutates in its relations with the world and that, therefore, cannot assume any higher hierarchical position in comparison to other existing beings. By doing so, the film makes possible for the viewer to embody a posthuman ecology, which describes subjects as agents within relational systems who continuously modify their condition through the encounters they make. However, the characters of the film, because of being dominated by their desires, are not active agents in these processes of becoming, but passive subjects who try to use these transformations for personal, self-destructive purposes. Consequently, the film demolishes the "too human" illusions of Dora, of the Queen, of Imma and of the King of Highhills by making the viewers perceive how they reflect the affective nature of human intellection and how they cannot be dominated by a transcendent mind that rejects its connection with the world. It is again the narcissistic closure of the characters and the consequently self-centered nature of their desires that prevents them from really opening their identities to an affirmative transformation, which would create new connections and regenerate the affection for their relatives.

In conclusion, by combining all the elements previously examined it can be affirmed that Tale of Tales as a whole interactive experience demonstrates that audiovisual media work by integrating affection and intellection, and give viewers the opportunity to interact with complex philosophical notions through embodied simulation and conceptual associations. Therefore, film experience constitutes an active deterritorialization, a becoming into a new experiential and performative dimension with its own affective and conceptual coordinates, which we embody and interact with. Moreover, Tale of Tales gives us the possibility to concretely experiment our ecological condition and the desire and necessity for becoming involved in every encounter we make. However, by employing our empathic and simulative qualities, we can use the negative elements of the narration as affirmative stimuli, thus not remaining passive subjects of our emotions, as the characters of the story do, and becoming creative actors in our relation with films. Indeed, a further effective suggestion on our posthuman condition comes with the final images of the film showing the exhibition of a funambulist (maybe a Nietzschean remembrance) hanging in the balance, we 
could argue, between the Vitruvian Man, who we should finally declare dead, and its ecological and baroque heir.

\section{References}

Basile, Giambattista. 1995. Lo cunto de li cunti [The Tale of Tales]. Milano: Garzanti.

Braidotti, Rosi. 2013. The Posthuman. Cambridge: Polity Press.

Coëgnarts, Maarten and Kravanja Peter. 2015. Embodied Ethics and Cinema: Moral Attitudes Facilitated by Character Perception. In Embodied Cognition and Cinema, eds. Maarten Coëgnarts and Peter Kravanja, 271-293. Leuven: Leuven University Press.

D’Aloia, Adriano and Eugeni Ruggero. 2015. Neurofilmology: An Introduction. CINÉMA\&CIE: International Film Studies Journal vol. 14, no. 22-23: 9-26.

Fahlenbrach, Kathrin. 2007. Embodied Spaces: Film Spaces as (Leading) Audiovisual Metaphor. In Narration and Spectatorship in Moving Images, eds. Joseph D. Anderson and Barbara Fisher Anderson, 105-121. Newcastle: Cambridge Scholars Publishing.

Garrone, Matteo. 2015. Con il Racconto dei Racconti porto Hollywood nella mia Terra [With Tale of Tales I bring Hollywood to my Land]. https://www.youtube. com/watch?v=8xBeZML6wac. Last accessed 30. 01. 2017.

Gallese, Vittorio. 2003. The Manifold Nature of Interpersonal Relations: The Quest for a Common Mechanism. Philosophical Transactions of the Royal Society B: Biological Science no. 358: 517-528.

Gallese, Vittorio and Michele Guerra. 2015. Lo schermo empatico: Cinema e neuroscienze [The Empathic Screen: Cinema and Neuroscience]. Milano: Raffaele Cortina Editore.

Morari, Codruța-Elena. 2007. Forms Mirroring Feelings: Iconicity and Empathy in Visual Metaphors and Non-Narrative Structures. In Narration and Spectatorship in Moving Images, eds. Joseph D. Anderson and Barbara Fisher Anderson, 92-104. Newcastle: Cambridge Scholars Publishing.

Plantinga, Carl. 2014. Moods and Ethics in Narrative Film. In Cognitive Media Theory, eds. Ted Nannicelli and Paul Taberham, 106-123. New York: Routledge. Ravven, Heidi Morrison. 2003. Spinoza's anticipation of contemporary affective neuroscience. Consciousness \& Emotion vol. 4, no. 2: 257-290.

Smith, Murray. 2004 [1995]. Engaging Characters: Fiction, Emotion and the Cinema. New York: Oxford University Press. 
Smith, Murray. 1999. Gangsters, Cannibals, Aesthetes or Apparently Perverse Allegiances. In Passionate Views: Film, Cognition, and Emotion, eds. Carl Plantinga and Greg M. Smith, 217-238. Baltimore: Johns Hopkins University Press.

Spinoza, Baruch. 2011. Tutte le Opere [Collected Works]. Milano: Bompiani Editore.

\section{List of Figures}

Figure 1. The Queen of Longtrellis eating the heart of the aquatic dragon. The colour contrasts reinforce the brutality of the sequence and the animalistic aspects of the character.

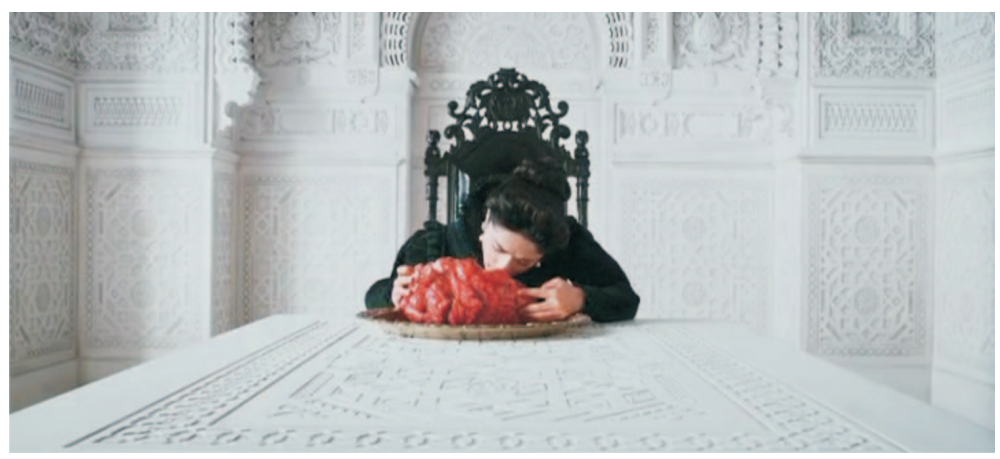

Figure 2. Imma at Dora's wedding party. She is positioned at the centre of the frame while observing with marvel the luxurious environment surrounding her. Viewers also access this context by simulating Imma's actions and her facial mimicry.

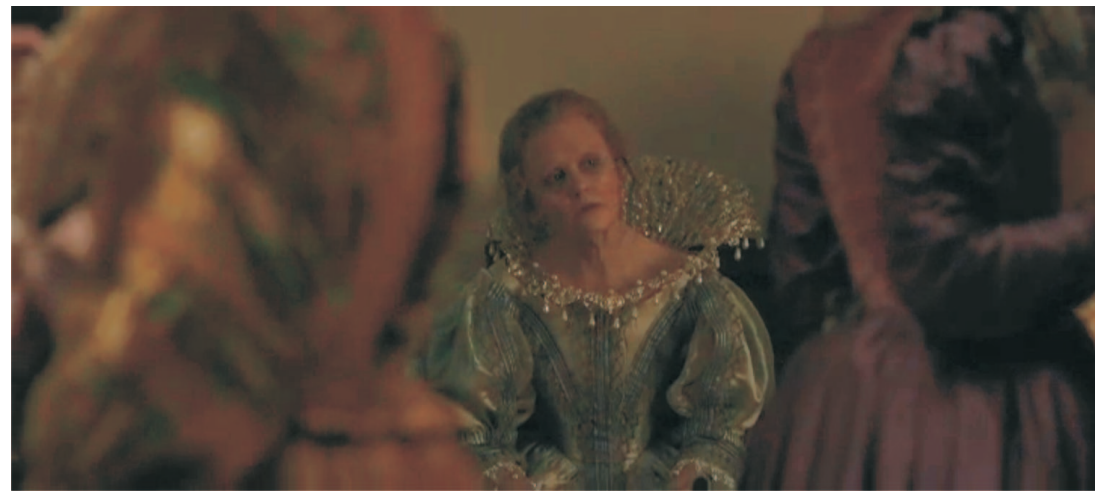


Figure 3. Imma, astonished, admires the transformation of Dora into a beautiful young woman, and starts desiring to mutate as her sister did. The two women, eventually, will both be destroyed by their desires.

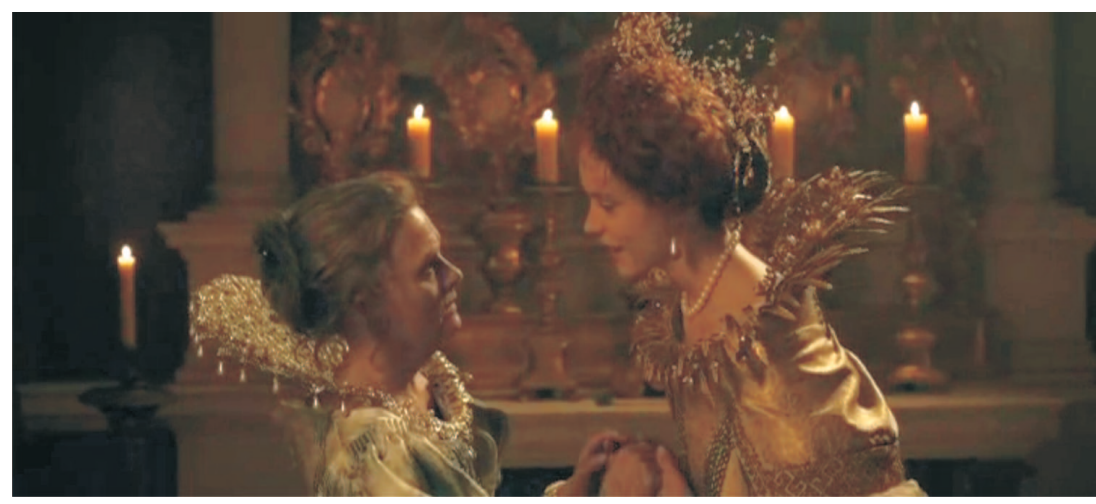

Figure 4. The death of the flea, and the affective bond between the King of Highhills and the animal. Here we can observe a clear connection between the human and animal, and a becoming-animal of the king, who, nonetheless, lives this bond as a morbid passion.

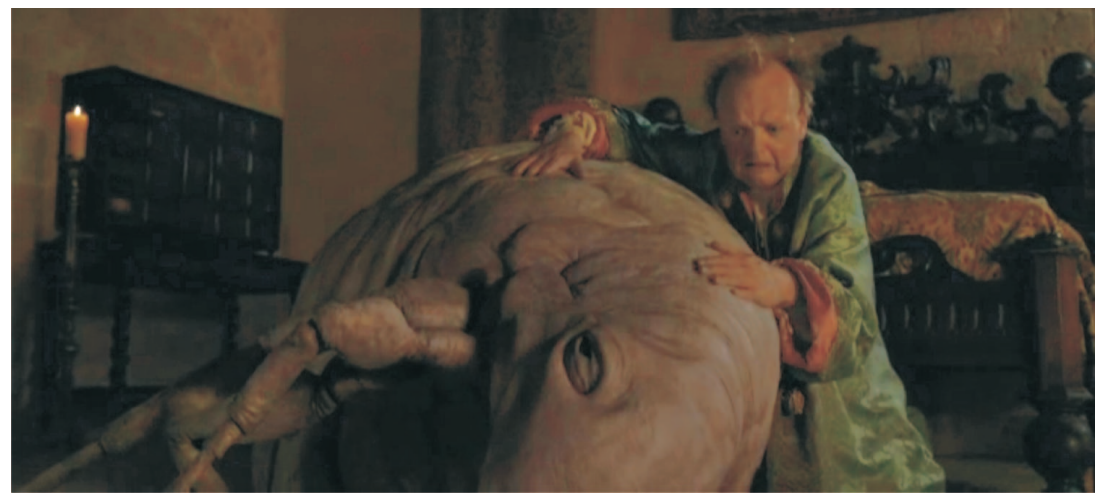

